\begin{tabular}{ccc}
\hline International Journal of Current Research in \\
Biosciences and Plant Biology \\
Volume $4 \cdot$ Number 8 (August-2017) $\bullet$ ISSN: 2349-8080 (Online) \\
PUCLLLENT
\end{tabular}

\title{
Comparison between Populations of Black Pied and Holstein Cows and Stud Bulls from Russia, Belarus and Kazakhstan by the Genetic Markers for Resistance to Leukemia
}

\author{
Zalina Latypova ${ }^{1}$, Sholpan Sarbakanova ${ }^{1}$, Saltanat Mamanova $^{1}$, Akhmetzhan Sultanov ${ }^{1}$, \\ Irina Nam², Irina Smaznova ${ }^{3}$, Vladimir Zayakin ${ }^{3}$ and Alexandre Kozlov ${ }^{3}$
}

\begin{abstract}
${ }^{1}$ Kazakh Scientific-Research Veterinary Institute, 050016, Republic of Kazakhstan, Almaty, Rayimbek Ave., 223
${ }^{2}$ Center for Innovation Transfer, Saint-Petersburg Academy of Veterinary Medicine, Russian Federation, Saint-Petersburg, Chernigov Str., 5

${ }^{3}$ Department of Chemistry, Bryansk State University named after Academician I.G. Petrovsky, Russian Federation, Bryansk, Bezhizk Str., 14
\end{abstract}

*Corresponding author.

\section{Abstract}

Leukemia is one of the most common infectious diseases of cattle in Russia and Kazakhstan. The study is devoted to the analysis of genetic resistance to leukemia by PCR-RFLP in 716 cows (including 75 RID+ cows and 27 cows with hematological changes) and 81 Black Pied and Holstein stud bulls from the Bryansk and Leningrad regions (Russia), Kazakhstan and Belarus. To this end, we have examined the allele frequencies of BoLA-DRB3 gene related to the resistance (R) and susceptibility (S) to leukemia in various groups of animals. Cows from the breeding farms have 44.1-55.2\% of $\mathrm{S}$ alleles, associated with susceptibility to leukemia, in the commercial farms they make up 20.1-29.4\%. The total number of susceptibility $\mathrm{S}$ alleles in stud bulls ranges from $49.9 \%$ to $70.9 \%$. In cows of all groups, the number of resistance alleles $\mathrm{R}$ to leukemia is far greater than in the bulls of all groups. It was shown that the number of $\mathrm{S}$ allele carriers is greater among RID+ cows. Analysis of 2 groups of sick cows has revealed that they include no animal units with RR genotype and only by $11-12 \%$ of cows with genotype $\mathrm{R} / \mathrm{S}$ and $\mathrm{R} / \mathrm{N}$. The findings suggest the accumulation of $\mathrm{S}$ alleles to leukemia under holsteinization of the Black Pied breed, with increased risk of developing leukemia in animals.
\end{abstract}

\section{Introduction}

One of the major issues of present-day animal husbandry in Russia and Kazakhstan is wide spread occurrence of leukemia virus in cattle herds. Leukemia causes great damage to animal husbandry, especially the

\section{Article Info}

Accepted: 24 July 2017

Available Online: 06 August 2017

\section{Keywords}

Black pied cows

BoLA-DRB3 gene

Genetic resistance

Holstein cows

Leukemia 
breeding and commercial farms. The Bryansk region is relatively prosperous as compared with other regions of Russia; in 2013, 6.3\% of seropositive animals were detected, the virus carrying was recorded in 162 farms of the region. In some commercial farms there is a high level of the cattle viral affection - up to $80 \%$ (Smaznova, 2015).

According to monitoring conducted in 2015 in Kazakhstan, the overall level of BLV affection in cows is about $4.4 \%$, the maximum amount of virus carrier cows was found in the North-Kazakhstan region (21.4\%), 2 regions of 16 are free from leukemia, and in another 9 regions the number of RID-positive cows is below 5\% (Mamanova et al., 2015).

It is known that a number of certain dangerous diseases in cows are transmitted genetically, for example, CVM and BLAD; in various European countries $6-40 \%$ of these latent carriers of genetic abnormalities were found among the stud bulls (Satsuk, 2009a).

Previously it was established that polymorphism in the BoLA-DRB3 exon 2 correlates with resistance to persistent lymphocytosis caused by bovine leukemia virus (Lewin and Bernoco, 1986; Xu et al., 1993; Zanotti et al., 1996; Takeshima and Aida, 2006; Behl et al., 2012). Genetic mechanisms of resistance and susceptibility to leukemia in Ayrshire and Black Pied cattle breeds were determined by allelic distribution of the BoLA-DRB3 gene.

It has been established that the animals carrying alleles $* 22, * 24, * 16, * 8$ are susceptible to leukemia (S), and they more often than others appear in the sample of hematological patients. Individuals with alleles $* 11$, $* 23, * 28$ are resistant to leukemia (R) (Sulimova et al., 1995; Mirsky et al., 1998; Udina et al., 2003; Nam et al., 2015). Resistance alleles are dominant, and the animals carrying them in the heterozygous state, do not develop leukemia. Neutral alleles are not associated with resistance or susceptibility to persistent lymphocytosis (Licursi et al., 2002; Aida et al., 2011).

Black Pied cattle is the most common breed in Russia, Belarus and Kazakhstan, therefore the study on genetic resistance/susceptibility to leukemia in Black Pied cows is of great importance for the livestock husbandry in these countries (Kovalyuk, 2008; Satsuk, 2009b). Evaluation of Holstein stud bulls is particularly important, because they are used to increase milk production, and may affect the cow resistance to leukemia. We have previously examined allelic polymorphism of the BoLA-DRB3 gene in Black Pied and Simmental cows from breeding farms of the Bryansk region, free of virus carriers, and their genetic resistance to leukemia (Smaznova et al., 2010; Kozlov et al., 2011). Genetic resistance to leukemia was studied in Holstein stud bulls from Russia and Belarus by the frequency of resistance and susceptibility alleles (Nam et al., 2014; Smaznova, 2015).

The aim of this work is to study the allelic polymorphism of the BoLA-DRB3 gene in Black Pied cows and Black Pied and Holstein stud bulls from Russia, Belarus and Kazakhstan and compare these groups of animals in their resistance and susceptibility to leukemia.

\section{Materials and methods}

The blood samples of Black Pied cows from Bryansk (590 heads) and Kazakhstan (126 heads) and sperm samples of Holstein stud bulls from the Bryansk (29 bulls) and Leningrad regions (29 bulls), Belarus (12 bulls) and Kazakhstan (11 bulls) were examined in this work.

DNA from leukocytes and bull sperm was isolated using the standard procedure. To identify the BoLA-DRB3 gene polymorphism by PCR-RFLP, the gene fragment of 284 bp length was amplified using the HLO30 and HLO32 primers. 284 bp fragment was hydrolyzed by restriction endonucleases Rsa I, Hae III and Bst IY (Smaznova, 2015). Electrophoresis of restricted DNA fragments was carried out at a current strength of 50-100 $\mathrm{mA}$, electric field strength of 100-150 V, the DNA fragment separation lasted 1.5-2 hrs. Ethidium bromide was added to agarose gel to visualize the DNA fragments.

\section{Results and discussion}

The BoLA-DRB3 gene allelic polymorphism was studied using PCR-RFLP method in 7 groups of Black Pied cows from Russia and 1 group from Kazakhstan, as well as in Black Pied and Holstein stud bulls from Russia (Bryansk and Leningrad regions), Belarus and Kazakhstan; the total number of examined animals is shown in Table 1.

The highest holsteinization grade is observed in the group Cows - Breeding farm 1, which is one of the best 
farms in the Bryansk region. Holsteinization grade in the group Cows - Breeding farm 2 is lower; the group Cows

- Commercial farm 3 is a commercial dairy farm, and the group Individual herd 4 comprises the cows that belong to various hosts, it is a random sample of animals.

Table 1. Groups of cows and stud bulls from various regions for analysis of BoLA-DRB3 gene alleles.

\begin{tabular}{llll}
\hline S.No. & Cattle group & Symbolic representation & Number of animals \\
\hline 1 & Cows - Breeding farm 1 & K-Br -1 & 52 \\
2 & Cows - Breeding farm 2 & K-Br -2 & 185 \\
3 & Cows - Commercial farm 3 & K-Br -3 & 63 \\
4 & Cows - Individual herd 4 & K-Br -4 & 81 \\
5 & Cows - Kazakhstan & K-Kaz & 126 \\
6 & Bulls - Leningrad region & B-Len & 29 \\
7 & Bulls - Belarus & B-Bel & 12 \\
8 & Bulls - Bryansk region & B-Br & 29 \\
9 & Bulls - Kazakhstan & B-Kaz & 11 \\
10 & Cow - RID- & K-R- & 107 \\
11 & Cows - RID+ & K-R+ & 75 \\
12 & Sick cows, group 1 & SK-1 & 8 \\
13 & Sick cows, group 2 & SK-2 & 19 \\
\hline & Total & & 797 \\
\hline
\end{tabular}

The groups of stud bulls include all Holstein and Black Pied bulls from the breeding station of the Bryansk region and Holstein bulls from the Leningrad region, Belarus (Minsk region) and Kazakhstan (Almaty region).

Earlier, when examining these animals, we have shown that 16 to 25 out of 54 possible alleles were revealed in different groups of cows, the total number of identified alleles is 37. Groups of cows differ considerably from each other in occurring alleles, the allele distribution within each group is uneven - alleles sharply differ in the frequency of occurrence $-0.3 \%$ to $23.4 \%$. Analysis of allelic diversity in groups of the Bryansk, Leningrad and Byelorussian bulls showed that 9-10 alleles were identified in the Holstein stud bulls from Leningrad region, Belarus and Kazakhstan, 15 alleles in the Bryansk holsteinizated Black Pied bulls. In general, it was concluded that the maximum number of alleles is observed in the Black Pied cows from the commercial dairy farms with low milk yields, the lowest number of alleles is observed in the Holstein bulls from Belarus, Kazakhstan and Leningrad region, purchased abroad and having high potential for milk production (Smaznova, 2015).

In the present study, we have compared alleles $* 8, * 16$, $* 22$, *24 which determine susceptibility to leukemia in different groups of cows and bulls (Table 2).

Table 2. Distribution of BoLA-DRB3 alleles associated with susceptibility to leukemia in different groups of cows and bulls.

\begin{tabular}{|c|c|c|c|c|c|}
\hline \multirow{2}{*}{ Animal group } & \multicolumn{5}{|c|}{ Frequency of leukemia susceptibility alleles of BoLA-DRB3 gene, \% } \\
\hline & $* 8$ & $* 16$ & $* 22$ & $* 24$ & Total \\
\hline \multicolumn{6}{|c|}{ Cows } \\
\hline Cows - Kultura & 9.6 & 5.3 & 16.0 & 23.4 & 54.3 \\
\hline Cows - Novy Put & 10.2 & 9.9 & 10.2 & 13.8 & 44.1 \\
\hline Cows - Snezhka & 9.0 & 1.6 & 5.7 & 13.1 & 29.4 \\
\hline Cows - Zhiryatino & 7.7 & 5.6 & 3.1 & 3.7 & 20.1 \\
\hline Cows - Kazakhstan & 4.8 & 19.4 & 16.7 & 14.3 & 55.2 \\
\hline \multicolumn{6}{|c|}{ Bulls } \\
\hline Bulls - Leningrad & 1.7 & 25.9 & 13.7 & 25.9 & 67.2 \\
\hline Bulls - Bryansk & 6.9 & 12.0 & 19.0 & 22.4 & 70.8 \\
\hline Bulls - Belarus & 12.5 & 16.7 & 8.3 & 33.3 & 60.3 \\
\hline Bulls - Kazakhstan & 22.7 & & & & 49.9 \\
\hline
\end{tabular}

As shown in Table 2, the cows from the Breeding farms 1,2 and the Kazakhstan susceptibility alleles ranged from $44.1 \%$ to $54.3 \%$, while in the less holsteinizated Commercial farm 3 and Individual herd 4 their number 
ranged within $20.1 \%-29.4 \%$. Alleles $* 22$ and $* 24$ were prevalent in the Breeding farms 1, while in the Individual herd 4 the leukemia susceptibility alleles were less common $-7.7 \%$ or below. Alleles $* 16$ and $* 22$ are of frequent occurrence in cows from Kazakhstan, while $* 16$ is the predominant allele.

In groups of bulls the total content of the leukemia susceptibility alleles is represented as follows (Table 2): $60.3 \%$ in the Bryansk herd, $67.2 \%$ in the Leningrad region,
$70.9 \%$ in the bulls from Belarus, with the predominance of $* 16, * 22, * 24$ alleles, while $* 24$ is the most frequent allele. In the Kazakh Holstein bulls, there are less of them $49.9 \%$, at that $* 8$ is the most frequent allele, $* 16$ and $* 24$ alleles by $13.0 \%, * 22$ allele is unavailable, which distinguishes the Kazakh bulls from the cows.

Frequency of occurrence for $* 11, * 23, * 28$ alleles, determining resistance to leukemia, is shown in the table (Table 3).

Table 3. Distribution of BoLA-DRB3 alleles associated with resistance to leukemia in different groups of cows and bulls.

\begin{tabular}{|c|c|c|c|c|}
\hline \multirow{2}{*}{ Animal group } & \multicolumn{4}{|c|}{ Frequency of leukemia resistance alleles of BoLA-DRB3 gene, \% } \\
\hline & $* 11$ & $* 23$ & $* 28$ & Total \\
\hline \multicolumn{5}{|c|}{ Cows } \\
\hline Cows - Kultura & 16.0 & 3.2 & 3.2 & 22.4 \\
\hline Cows - Novy Put & 9.7 & 8.8 & 2.8 & 21.3 \\
\hline Cows - Snezhka & 13.9 & 16.4 & 4.1 & 34.4 \\
\hline Cows - Zhiryatino & 8.0 & 9.3 & 4.9 & 22.2 \\
\hline Cows - Kazakhstan & 6.0 & 14.3 & 2.8 & 23.1 \\
\hline \multicolumn{5}{|c|}{ Bulls } \\
\hline Bulls - Leningrad & 1.7 & 6.9 & 3.5 & 12.1 \\
\hline Bulls - Bryansk & 8.6 & 8.6 & 1.7 & 8.4 \\
\hline Bulls - Belarus & 4.2 & 0 & 4.2 & 18.9 \\
\hline Bulls - Kazakhstan & 4.5 & 0 & 0 & 4.5 \\
\hline
\end{tabular}

In cows from different groups, the total frequency of leukemia resistance alleles ranges from $21.3 \%$ to $34.4 \%$; $* 11$ and $* 23$ alleles are the most frequent. In the stud bull groups, there are much less resistance alleles, most of them are observed in the Bryansk bulls (19.1\%), $12.1 \%$ in the Leningrad animals, and $8.4 \%$ in the Belarusian bulls. In the Kazakh bulls only *11 of 3 resistance alleles is available in a minimum number of $4.5 \%$, that is, only one bull has it in the heterozygous state. It is possible that the other alleles are associated with resistance to leukemia in the Kazakh bulls, by analogy with the Ayrshire breed, in which $* 7$ allele is responsible for resistance to leukemia (Kovalyuk, 2008; Sazuk, 2009b).

Comparison of animal groups by the total number of susceptibility and resistance alleles is pictured in Fig. 1.

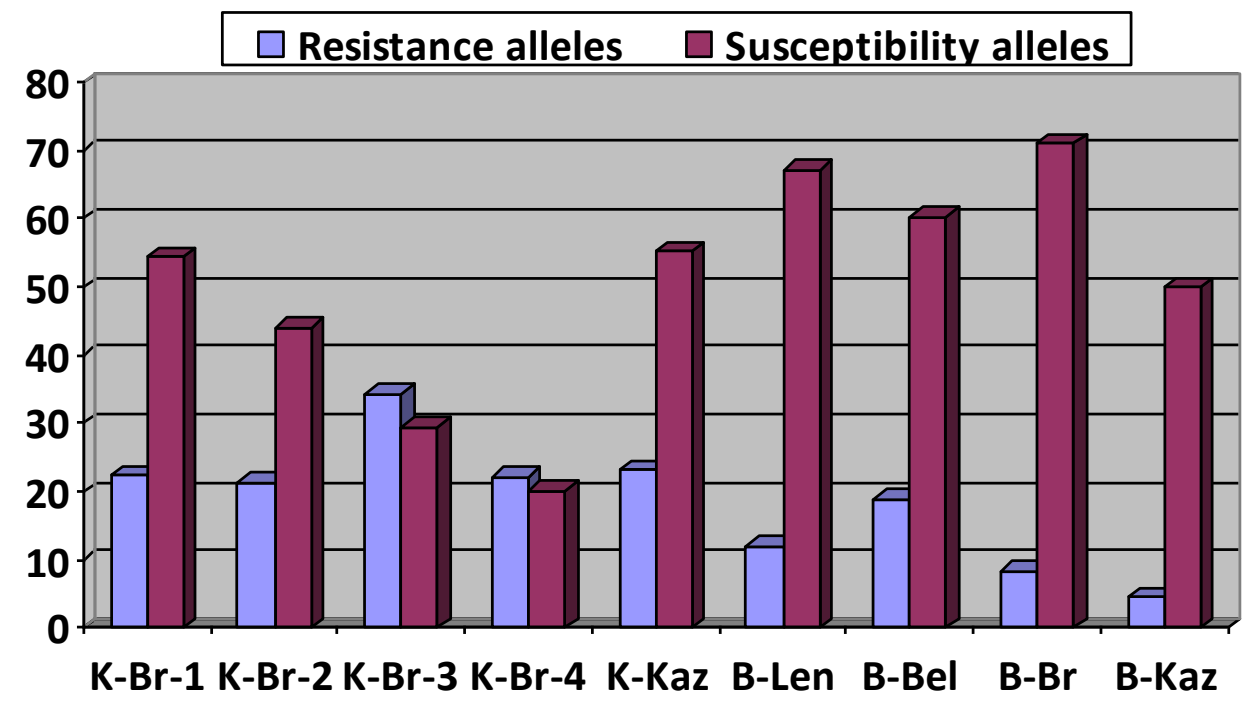

Fig. 1: Frequency of occurrence of susceptibility and resistance alleles to leukemia. 
As shown in Fig. 1, there is a clear general tendency to changes in the frequency of susceptibility and resistance alleles by the groups: with increasing holsteinization grade of Black Pied animals the number of susceptibility alleles increases and the number of resistance alleles reduces.

We have examined the distribution of susceptibility and resistance alleles to leukemia in healthy, RID+ and 2 groups of sick cows (with hematological changes), the data are pictured in Fig. 2.

The data given in Fig. 2 maintain the conclusion that the bovine leukemia virus more often affects the cows with susceptibility alleles, the maximum number of resistance alleles was identified in the group of healthy cows (Zanotti et al., 1996; Udina et al., 2003).

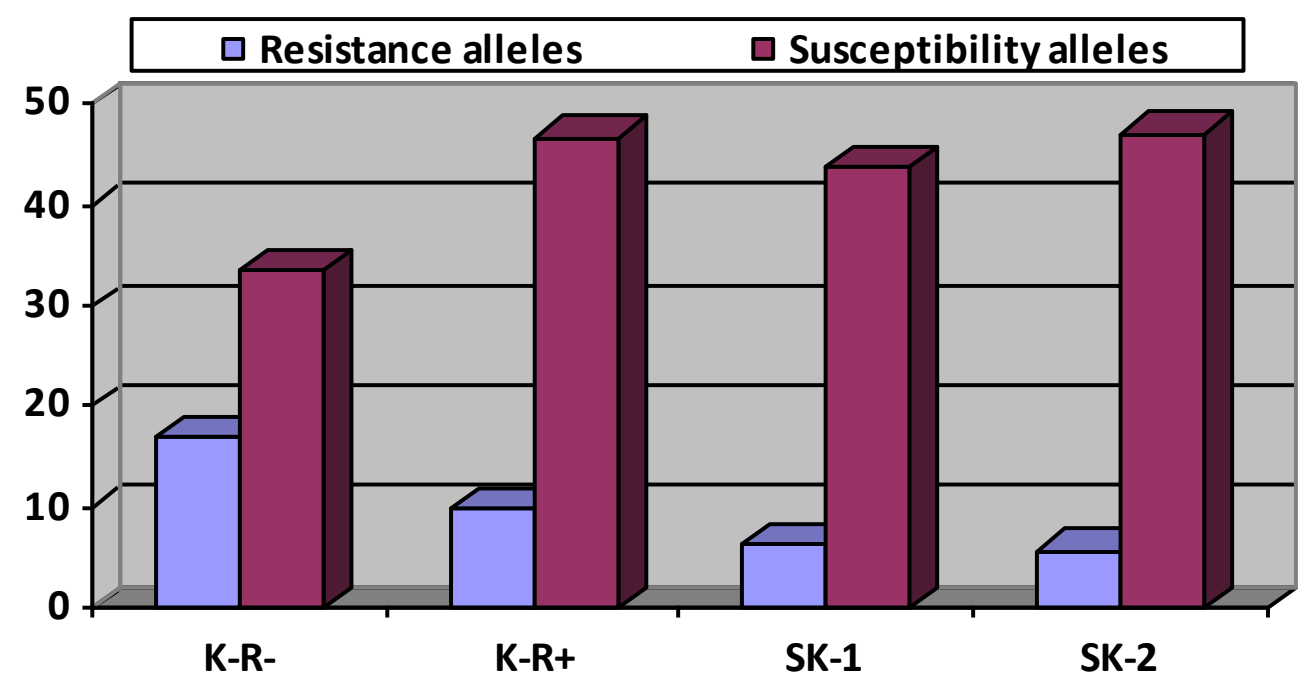

Fig. 2: Frequency of susceptibility and resistance alleles in groups of healthy, virus carrier and sick cows.

It is known that the resistance alleles take the dominant position, therefore the animals carrying them in the heterozygous state, do not develop leukemia. We have compared the genotypic structure of the BoLA-DRB3 gene in groups of cows and stud bulls. Fig. 3 shows the frequency distribution of cows and bulls in all 9 groups by the genotypes: resistant to leukemia ( RR + RN + RS), homozygous for the leukemia susceptibility alleles (SS), homozygous for the neutral genes $(\mathrm{NN})$, and heterozygous (NS).

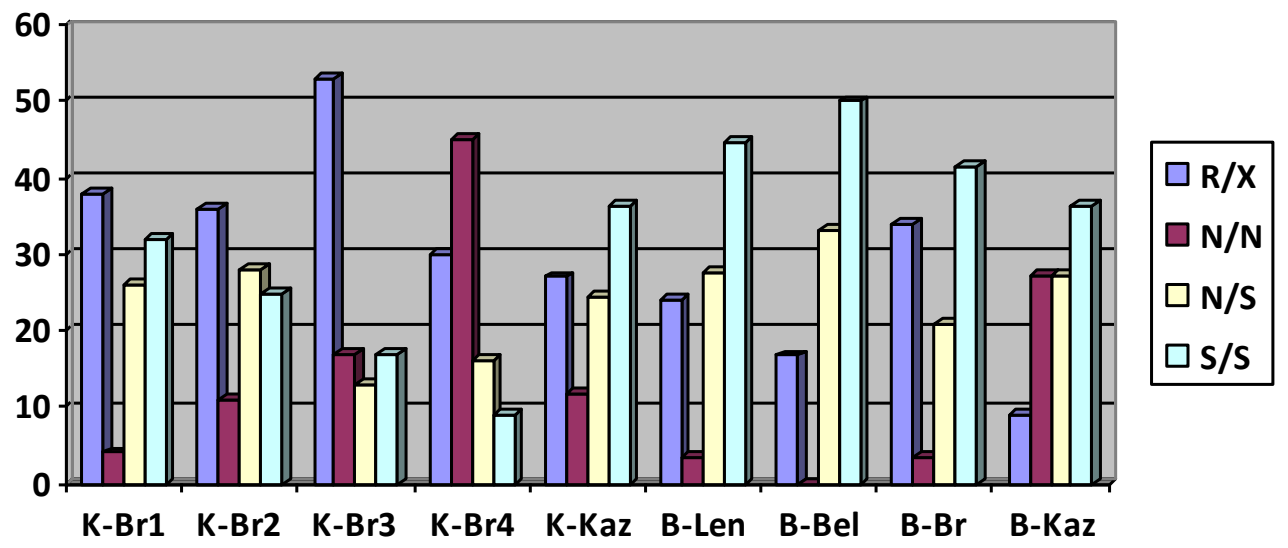

Fig. 3: Distribution of animal genotypes by resistance to leukemia in groups of Black Pied cows and bulls.

The study data suggest the following conclusions: most of genotypes resistant to leukemia were found in the commercial dairy herd $-53 \%$, in the three other groups of the Bryansk region their number reached $30 \%-38 \%$, in the Kazakh herd of cows $-27 \%$.

Most of genotypes resistant to leukemia are observed in the Bryansk bull group - $34 \%$, the minimal number of 
$9.1 \%$ - in the Kazakh group. In all 4 groups there are no bulls with RR genotype carrying the resistance alleles in the homozygous state. The data indicate the predominance of bulls carrying susceptibility alleles in the homozygous state: $50 \%$ in the Belarusian, $44.8 \%$ in the Leningrad, $41.35 \%$ in the Bryansk, and $36.4 \%$ in the Kazakh bulls, i.e., there is a clear trend towards increase in this parameter with improvement in milk production.

\section{Conclusion}

Therefore, the study on allelic polymorphism of the BoLA-DRB3 gene showed a significant difference in the groups of Black Pied and Holstein cows and stud bulls from Russia, Belarus and Kazakhstan. The findings allow us to conclude that under holsteinization of Black Pied cattle the accumulation of leukemia susceptibility alleles is observed, inhibiting the formation of protective reactions, and associated with the spread of leukemia in populations. In the absence of animals - BLV carriers, this fact will not affect the epizootic situation, as is the case in Belarus, the Leningrad region and advanced countries of Europe.

However, in the presence of BLV infectious background in the farms (most of the Russian and Kazakhstan regions, some large farms in USA, Canada, South Korea and other countries) it will lead to a permanent increase in virus carrying and appearance of sick animals. Therefore, in order to protect the cattle stock in breeding and commercial farms against leukemia, it is necessary to develop a system of measures that take into account the genetic resistance of the breeding stock to leukemia, which is inherited from the highly productive stud bulls.

\section{Conflict of interest statement}

Authors declare that they have no conflict of interest.

\section{Acknowledgement}

This work was supported by the Ministry of Education and Science of the Russian Federation (grant № 41, task № 2014/426) and by the Ministry of Education and Science of the Republic of Kazakhstan (grant 4644/GF4 2015).

\section{References}

Aida, Y., Takeshima, S., Matsumoto, Y., Taku, M., Yoshiyuki, M., Yoshihiro, T., William, C.D., Okada,
K., 2011. Bovine MHC class II DR molecule plays a key role in bovine leukemia virus (BLV)-induced lymphoma. Retrovirol. 8(Suppl.1), A7.

Behl, J.D., Verma, N.K., Tyagi, N., Mishra, P., Behl, R., Joshi, B.K., 2012. The major histocompatibility complex in bovines: A review. ISRN Vet. Sci. 2012, 872710. 12p.

Kovalyuk, N. V., 2008. Molecular and Genetic Aspects of Selection and Early Leukemia Detection in Cattle, Doctorate of Biology Thesis.

Kozlov, A.L., Smaznova, I.A., Zayakin, V.V., Nam, I.Y., 2011. Analysis of the BoLA-DRB3 gene polymorphism in the simmental cattle breed. Proc. Samara Res. Centre Rus. Acad. Sci. 13(5), 248-250.

Lewin, H., Bernoco, D., 1986. Evidence for BoLAlinked resistance and susceptibility to subclinical progression of bovine leukaemia virus infection. Anim. Genet. 17, 197-207.

Licursi, M., Inoshima, Y., Wu, D., Yokoyama, T., Gonzalez, E., Sentsui, H., 2002. Genetic heterogeneiti among bovine leukemia virus genotypes and its relation to humoral responses in hosts. Virus Res. 86, 101-110.

Mamanova, S.B., Kutumbetov, L.B., Bakhtakhunov, L.B., Smaznova, I.A., Zayakin, V.V., Akhmedov, R.B., Nam, I.Ya., 2015. Development of a program for the elimination of leukemia of cattle in livestock farms in Russia, Kazakhstan and Kyrgyzstan on the basis of biotechnological approaches // Mater. I The Eurasian scientific-practical. Conf. "Innovative agrobiotechnology in livestock and veterinary medicine." pp.63-68.

Mirsky, M.L., Olmstead, C.Da., Lewin, H.A., 1998. Reduced bovine leukaemia virus proviral load in genetically resistant cattle. Anim. Genet. 29, 245252.

Nam, I.Ya., Zayakin, V.V., Smaznova, I.A., Egiazaryan, A.V., Sulimova, G.E., Sheiko, I.P., Budevich, A.I., 2014. High genetic susceptibility to leukemia in breeding black pied and holstein cattle // MiddleEast J. Scient. Res. 20(10), 1297-1301.

Nam, I.Ya., Zayakin, V.V., Smaznova, I.A., Kozlov, A.L., Achmedov, R.B., Kobozeva, M.S., 2015. The genetic polymorphism of BoLA-DRB3 gene and the resistance to virus leukemia in different herds of cattle at Bryansk region. Res. J. Pharmaceut. Biol. Chem. Sci. 6(1), 1903-1907.

Satsuk, V.F., 2009a. The Use of the BoLA-DRB3 Marker in Cattle Selection and Breeding, $\mathrm{PhD}$ Thesis.

Satsuk, V.F., 2009b. Use of the BoLA-DRB3 marker in 
the selection and breeding work with cattle: Cand. Diss. in Biol. Sci. Stavropol: 118 p. / Satsuk VF, 2009. Using the marker BoLA-DRB3 in selection and breeding work with cattle: Dis .... kand. Cand. Biol. Sciences. Stavropol. 118p.

Smaznova, I.A., 2015. Characterization of allelic polymorphism of the gene BoLA-DRB3 affecting resistance to leukemia, and genes of milk production of the bulls of the Bryansk region. PhD Thesis.

Smaznova, I.A., Kozlov, A.L., Zayakin, V.V., Nam, I.Ya., 2010. Allelic assay of the BOLA-DRB3 gene in the cattle herds of the Bryansk region. Bull. Bryansk State Univ. 4, 227-232.

Sulimova, G.E., Udina, I.G., Shankhaev, G.O., Zakharov, I.A., 1995. DNA polymorphism of the BoLA-DRB3 gene in cattle in connection with resistance and susceptibility to leukemia. Genetika. 31(9), 1294-1299.
Takeshima, S.-N., Aida, Y., 2006. Structure, function and disease susceptibility of the bovine major histocompatibility complex. Anim. Sci. J. 77, 138150.

Udina, I.G., Karamysheva, E.E., Turkova, S.O., 2003. Genetic mechanisms of resistence and susceptibility to leukemia in Ayrshire and Black Pied cattle breeds determined by allelic distribution of gene BoLADRB3. Rus. J. Genet. 39(3), 383-396.

Xu, A., van Eijk, M.J., Park, C., Lewin, H.A., 1993. Polymorphism in BoLA-DRB3 exon 2 correlates with resistance to persistent lymphocytosis caused by bovine leukemia virus. J. Immunol. 151(12), 6977-6985.

Zanotti, M., Poli, G., Ponti, W., 1996. Association of BoLA class II haplotypes with subclinical progression of bovine leukaemia virus infection in Holstein-Friesian cattle. Anim. Genet. 27(5),337-41.

\section{How to cite this article:}

Latypova, Z., Sarbakanova, S., Mamanova, S., Sultanov, A., Nam, I., Smaznova, I., Zayakin, V., Kozlov, A., 2017. Comparison between populations of Black Pied and Holstein cows and Stud bulls from Russia, Belarus and Kazakhstan by the genetic markers for resistance to leukemia. Int. J. Curr. Res. Biosci. Plant Biol. 4(8), 1-7. doi: https://doi.org/10.20546/ijcrbp.2017.408.001 